\title{
Base sustainable development goals on science
}

\section{Gisbert Glaser urges the United Nations' working group to do their research.}

$\mathrm{A}$ t the Rio+20 United Nations conference in June 2012, the world's governments agreed to produce a set of sustainable development goals (SDGs). Unlike the Millennium Development Goals (MDGs), which are targeted at poor and emerging nations, the SDGs will have a global reach. They will apply to developed and developing countries alike, and will concern the Earth system as well as people.

This week, governments meeting in New York will discuss SDGs ahead of the launch of the UN working group tasked with defining their scope and path. I call on the representatives of member states to put good scientific data at the heart of the process.

Human pressure on the Earth system may move us beyond safe natural boundaries. As the climate changes, biodiversity is lost and ecosystems decline, we are on course to interlinked environmental, economic and social crises that will make it difficult to provide the growing world population with food, water and energy. Only by setting human development on a sustainable trajectory will we safeguard Earth systems for future generations.

Science was short-changed at Rio+20, where green economy and institutional issues were at the fore. But decisions around complex issues such as water scarcity, ocean health, ecosystems and food security must be evidence-based. As a senior adviser to the International Council for Science (ICSU), headquartered in Paris, I feel it is crucial that the best available research underpins the development of goals, targets and indicators at global, regional and national levels. ICSU, having a special consultative status with the United Nations, has offered to provide scientific input to the working group, drawn from research communities worldwide.

Here I set out the steps that are needed to reach tractable goals that will drive sustainable development. These complement the Future Earth ten-year initiative for global sustainability research, which was launched at Rio +20 by the scientific community.

The SDG idea, put forward by Columbia and Guatemala in 2011, received widespread support at the Rio+20 conference. It builds on the MDG concept of setting voluntary, time-bounded targets. Some people are cynical about these, but I believe that the MDGs, even if not reached, have generated commitments and actions worldwide that would not otherwise have happened. For instance, the
MDG of halving between 1990 and 2015 the proportion of people whose income is less than US\$1 per day is on target.

\section{GLOBAL VISION}

The Rio+20 outcome document ${ }^{1}$ proposes that the SDGs must be "action-oriented, concise and easy to communicate, limited in number, aspirational, global in nature and universally applicable to all countries while taking into account different national realities, capacities and levels of development and respecting national policies and priorities".

Meeting all of these requirements will be a challenge for the UN working group. A major difficulty is the interdisciplinary nature of sustainable development. It cuts across economic, environmental and social dimensions in ways that are not well understood. An understanding of climate change, for example, will be necessary to define measures across water, food and energy security. The working group will need to draw on the best available knowledge to analyse these linkages, possible synergies and trade-offs.

The working group's first action must be an extensive information-gathering exercise. This must include all work already undertaken on SDGs, targets and indicators. The group should set up consultations in countries across a range of development levels and seek wide input, from civil society, business, industry and the scientific community.

The long-term strategy of the SDGs must be decided. Should they become the successor to the MDGs after 2015, as some

\section{SUSTAINABILITY}

\section{Proposed themes}

Goals suggested by Colombia, Peru

and the United Arab Emirates at Rio+20.

- Food security

- Integrated water management

- Energy for sustainable development

- Sustainable and resilient cities

- Healthy and productive oceans

- Enhanced capacity of natural

systems to support human welfare

- Improved efficiency and

sustainability in resource use

- Enhanced employment and

livelihood security countries have proposed? Or would this direct resources away from unmet MDGs? At Rio+20, all governments agreed that the SDGs should be "integrated into the United Nations development agenda beyond 2015”. I agree that is the way forward.

The goals should be built around crossdisciplinary themes such as food, water and energy security, rather than separate pillars of economy, environment and social development (see 'Proposed themes'). Overarching goals, such as the eradication of poverty, might also be included ${ }^{2}$ through a two-tier architecture: a handful of primary SDGs on top of a second layer of thematic ones.

The choice of primary goals is tied to the choice of measures of progress and human well-being. Economic indicators such as gross domestic product and the Human Development Index focus on the short term and fail to reflect the state of the environment and natural resources. Metrics must be based on 'inclusive wealth' - all forms of capital, from natural, social and human to financial and manufactured ${ }^{3}$. As shown by attempts to include ecosystem services and biodiversity within national metrics, this will not be easy.

Measuring progress on the SDGs will require agreed sets of indicators for use at national, regional and international levels and in developed and developing countries. Several have been proposed; none is currently in use everywhere ${ }^{4,5}$. Much more work is needed on science-based indicators.

As consumption accelerates and the world population rises, global sustainability must become a reality. Scientists must help the working group to devise a set of practical targets. Their adoption by the world's governments will be a test of political will.

Gisbert Glaser is a senior science-policy adviser to the International Council for Science in Paris, France. e-mail:gisbert.glaser@icsu.org

1. United Nations. The Future We Want (UN, 2012); available at http://go.nature.com/ppewxp.

2. Sachs, J. D. Lancet 379, 2206-2211 (2012).

3. UN University International Human Dimensions Programme \& UN Environment Programme (eds) Inclusive Wealth Report 2012 (Cambridge Univ. Press, 2012).

4. UN Department of Economic and Social Affairs Indicators of Sustainable Development: Guidelines and Methodologies. Third Edition (UN, 2007).

5. Hak, T., Moldan, B. \& Dahl, A. L. (eds) Sustainability Indicators: A Scientific Assessment SCOPE Series 67 (Island Press, 2007). 